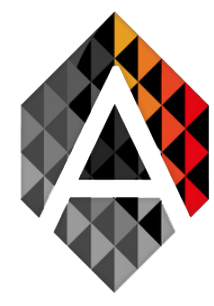

\title{
A Quality Innovation Strategy for an Inter-regional Digital Innovation Hub
}

\author{
Jonas Queiroz ${ }^{\mathrm{a}}$, Paulo Leitão ${ }^{\mathrm{a}}$, Joseane Pontes ${ }^{\mathrm{b}}$, André \\ Chaves $^{\mathrm{a}}$, Javier Parra-Domínguez ${ }^{\mathrm{c}}$ and María E. Perez-Pons ${ }^{\mathrm{c}}$ \\ ${ }^{a}$ Research Centre in Digitalization and Intelligent Robotics (CeDRI), Instituto Politécnico \\ de Bragança, Campus de Santa Apolónia, 5300-253 Bragança, Portugal. \\ b Universidade Tecnológica Federal do Paraná (UTFPR), Campus Ponta Grossa, Paraná, \\ Brasil. \\ c BISITE Research Group, University of Salamanca, Edificio Multiusos I+D+i, 37007 \\ Salamanca, Spain. \\ \{jpqueiroz, pleitao, a.chaves\}@ipb.pt; joseane@utfpr.edu.br; \\ \{javierparra, eugenia.perez\}@usal.es
}

KEYWORD

Digital

Innovation

Hub; Innovation

Management;

Quality

Innovation;

Digital

Technologies:

\section{ABSTRACT}

Industry 4.0 is reshaping the way all the economic sectors are working. The complete adoption and understanding by the companies, large or small, of the digital transformation opportunities and benefits, requires the existence of effective instruments. Digital Innovation Hubs (DIHs) are an important instrument, strongly promoted by the European Commission, to help companies to take advantage of digital opportunities. Aiming to boost and create synergies between several DIHs and research centers located in the northern region of Portugal and Spain, and considering the disruptive ICT technologies, the establishment of an inter-regional DIH that results from the cooperation between these entities assumes a crucial importance to transform this region into an innovative pole of reference. This paper aims to describe the strategy for the management and improvement of the quality of the innovation being developed by this inter-regional DIH under the scope of the DISRUPTIVE project. Besides considering the individual strategies of the associated members, it includes cooperative aspects, regarding the sharing of knowledge, technology, and skills, aiming to improve the quality of innovation, as well as the adoption of digitization by the companies in this region.
Jonas Queiroz, Paulo Leitão, Joseane Pontes, André Chaves, Javier Parra-Domínguez and María E. Perez-Pons A Quality Innovation Strategy for an Inter-regional Digital Innovation Hub
ADCAIJ: Advances in Distributed Computing and Artificial Intelligence Journal Regular Issue, Vol. 9 N. 4 (2020), 31-45 eISSN: 2255-2863 - https://adcaij.usal.es Ediciones Universidad de Salamanca - CC BY-NC-ND 


\section{Introduction}

In the context of the 4th industrial revolution, we are noticing the digital transformation of all economic sectors, allowing to increase productivity and competitiveness. This digital revolution introduces opportunities for large and small companies, but many of them still have a long way to implement the digital transformation, also having difficulties in understanding the true dimension of this transformation and which technologies will bring benefits to their business processes.

A recent survey focusing on companies from various industrial production sectors predicts an increase in the level of digitization and networking in industries by 2020 from $33 \%$ to $72 \%$ (Geissbauer et al., 2016), while other reports, e.g., (Blanchet and Rinn, 2016), point out an adoption rate of around $50 \%$ of the Industry 4.0 concepts, principles and technologies by 2035 for Western European countries. According to European Commission reports related to the "Shaping Europe's digital future" program (European Commision, 2020), only $20 \%$ of European companies are highly digitized, with $60 \%$ of large industries and over $90 \%$ of SMEs (Small and Medium Enterprises) being late in the adoption of the digital innovation.

In this context, Digital Innovation Hubs (DIHs) are an instrument that can help all companies, small or large, high-tech or not, to take advantage of digital opportunities. A DIH can be defined as a support service for companies to become more competitive in the context of digital transformation, allowing them to improve their production processes, through the automation or incorporation of disruptive and digital technologies. DIHs serve companies, taking into account their regional proximity, allowing the easier access to the latest knowledge, experience, technology, and innovation, as well as providing commercial and financial support to implement innovation in terms of business, production process, product or service, within the scope of digital transformation. Also, according to the "Shaping Europe's digital future" program, a DIH has 4 main functions: promote an innovation and networking ecosystem, provide skills and training, provide environments for prototyping and testing, and provide support to find investments (European Commision, 2020).

DIHs play an important role at the national and European level, being one of the main priorities of the "Digitising European Industry" initiative, adopted in April 2016, and will also have a central role in the "Digital Europe Programme", in the new EU financing cycle.

In this context, and considering the cross-border space between Portugal and Spain, it is possible to find several technological DIHs, namely, the DIH in the Internet of Things (IoT) located in Salamanca and focusing on IoT technologies, the DIH in Security located in León and focusing on the cyber-security topics, the DIH in Smart Cities located in Valladolid and addressing the smart and green cities topics, and the Hub4AGRI located in Portugal and focusing on the topic of digitization of agriculture.

Aiming to boost and create synergies between the various DIHs and research centers within the northern region of Portugal and Castilla y León (CyL-PN), and particularly in the DISRUPTIVE consortium, and considering the impulse of disruptive ICT (Information and Communication Technologies), the objective is to establish an inter-regional DIH that results from the cooperation between these entities in the cross-border region. Thus, the established inter-regional DIH will contribute to transform this region into an innovative pole of reference and strategic importance for the EU and with the potential to be internationally competitive.

In this context, the DISRUPTIVE consortium's role is to foster the generation of knowledge and excellence in research and innovation $(\mathrm{R}+\mathrm{i})$ to substantially boost innovation and technology transfer to improve the competitiveness of local companies. For this purpose, it is important not only to promote research and technological development activities but also to ensure the quality of production

Jonas Queiroz, Paulo Leitão, Joseane Pontes, André Chaves, Javier Parra-Domínguez and María E. Perez-Pons A Quality Innovation Strategy for an Inter-regional Digital Innovation Hub
ADCAIJ: Advances in Distributed Computing and Artificial Intelligence Journal Regular Issue, Vol. 9 N. 4 (2020), 31-45 eISSN: 2255-2863 - https://adcaij.usal.es Ediciones Universidad de Salamanca - CC BY-NC-ND 
and innovation of involved DIHs and research centers. In this sense, in addition to adopting innovation strategies, this inter-regional DIH should include methodologies and strategies for managing the quality of innovation that result from the contributions and individual strategies of the associated members, as illustrated in Figure 1.

Having this in mind, this article describes the methodology and strategy for managing the quality of innovation in the inter-regional DIH. The rest of the paper is organized as follows. Section 2 overviews the concept of quality innovation management and the available methodologies to support its implementation. Section 3 proposes a quality innovation strategy for the inter-regional DIH, considering the different strategies and perspectives of each associated DIH and research center. Finally, Section 4 rounds up the paper with the conclusions and points out the future work.

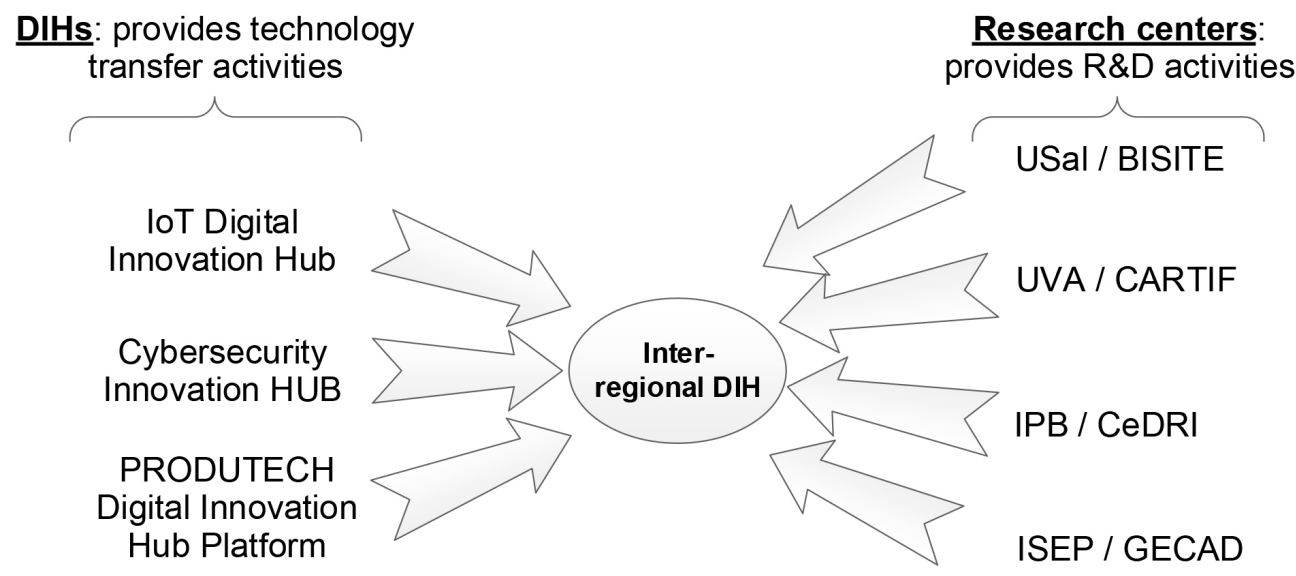

Figure 1: Inter-regional DIH as result of the cooperation of several DIHs and research centers.

\section{Overview of Quality and Innovation Concepts}

Similar to innovation, the concept of quality can be considered dynamic and linked to the human perception's complexity, and can be characterised by the evolution of the various quality areas, such as inspection, statistical quality control, quality assurance, and strategic quality management (Paladini, 2012).

Throughout the history of quality, the concepts evolved from the historical moment and the predominant vision of each epoch or Era of Quality (Carpinetti, 2016). According to (Garvin, 1992), similarly to innovation, quality has five main approaches: the transcendent philosophy approach, the product-based approach, the consumer-based approach, the value-added approach, and the production-based approach. According to (Carpinetti, 2016), quality will only play a competitive role if it can transcend the customer expectations, i.e. using the innovation of services, processes, products to surprise customer expectations (Garvin, 1992). In this sense, the concepts of quality and innovation can

Jonas Queiroz, Paulo Leitão, Joseane Pontes, André Chaves, Javier Parra-Domínguez and María E. Perez-Pons A Quality Innovation Strategy for an Inter-regional Digital Innovation Hub
ADCAIJ: Advances in Distributed Computing and Artificial Intelligence Journal Regular Issue, Vol. 9 N. 4 (2020), 31-45 eISSN: 2255-2863 - https://adcaij.usal.es Ediciones Universidad de Salamanca - CC BY-NC-ND 
be considered important factors to promote value creation, customer focus, and return on investment for the organization, besides being essential to boost the competitiveness of organizations (Garvin, 1992).

\subsection{Innovation Concept}

Innovation is related to novelties or improvements, whether in products, services, technologies or processes. Unlike new/creative ideas or invention, innovation involves the successful and practical realization of something original or more effective than something that already exists, and which has a significant impact on the market or society (Forbes, 2015; Amabile and Pratt, 2016).

Similar to the concept of quality, there are multiples definitions for innovation, which varies according to the type of organization. In the following, two examples are presented:

- "Innovation is the multi-stage process whereby organizations transform ideas into new/improved products, service or processes, in order to advance, compete and differentiate themselves successfully in their marketplace." (Baregheh et al., 2009)

- "An innovation is the implementation of a new or significantly improved product (goods or service), or process, a new marketing method, or a new organisational method in business practices, workplace organisation or external relations." (OECD/Eurostat, 2018)

Beyond the definition, the innovation can be classified by different aspects. For instance, the Organisation for Economic Co-operation and Development (OECD) Oslo Manual defines four types of innovations that comprehend the introduction of new or significantly improved Product (goods or services), Process (production or delivery method), Marketing method (physical design, packaging, placement, advertisement), and Organizational method (business practices, workplace organization, relationship management) (OECD/Eurostat, 2018).

Another classification is presented by (Edison et al., 2013), that also divides the innovation in four types, according to the degree of novelty, impact or disruption regarding the existing solutions, as illustrated in Figure 2.

Technological:
based on significantly
different technologies,
but offering similar
benefits compared to
existing solutions

Incremental: based
on existing
technology, with small
changes or new
features that brings
some benefits

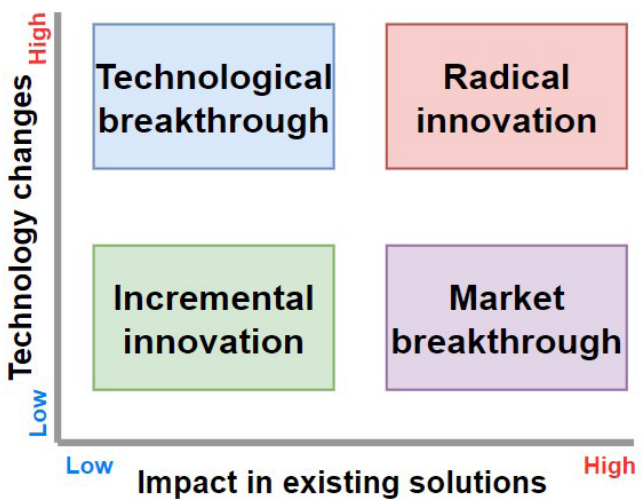

Radical: or disruptive. Based on new technologies and provides completely new solutions or features that brings significative benefits that can transform or create new markets.

Market: based on consolidated technology, similar to existing solutions, but providing significative benefits

Figure 2: Types of innovation regarding technology changes and impact in existing solutions.

Jonas Queiroz, Paulo Leitão, Joseane Pontes, André Chaves, Javier Parra-Domínguez and Maria E. Perez-Pons A Quality Innovation Strategy for an Inter-regional Digital Innovation Hub
ADCAIJ: Advances in Distributed Computing and Artificial Intelligence Journal Regular Issue, Vol. 9 N. 4 (2020), 31-45 eISSN: 2255-2863 - https://adcaij.usal.es Ediciones Universidad de Salamanca - CC BY-NC-ND 


\subsection{The Innovation Process}

Although innovations can be classified as mentioned above, it is noticeable that regardless of their classification, they all follow a process for innovation. The generation of new ideas is the basis for innovation, but if they are not realized (developed and implemented) they are just ideas. Usually, this process comprises several stages, which must support transforming a potential idea into a successful innovation (i.e., something that adds value for individuals, society or organisation). In general, it can be summarised in 3 main phases, as shown in Figure 3.

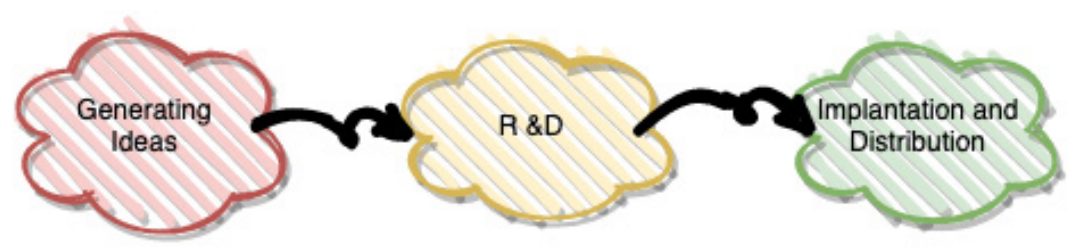

Figure 3: The 3 essential stages of an innovation process.

- Generating Ideas (Ideation) - represents an essential stage which, in addition to creativity, may require various skills and knowledge. In general, innovative ideas arise to meet existing problems or needs, which requires not only general but also technical knowledge to understand what exists (problems, demands, trends, structural/cultural evolution) and propose solutions (new or improved) in order to create and choose ideas with the potential to be realised and to succeed. There are several tools to support the generation and choice of ideas, which can be part of a framework to manage innovation.

- $R \& D$ - represents the engineering process to turn an idea into something usable (and adding value), be it a product, service, or process. While in the first phase, there is an interaction with end users to understand the demands and possibilities of adopting the new approaches, in this phase, the interaction is focused on the refinement of the solution to meet better and consequently achieve greater adoption and impact. At the end of this phase, an invention is obtained, which is only considered as innovation when it has an effect on organisations, the market, or society.

- Deployment \& Dissemination - requires a business model, as well as communication strategy to address end users with the need to realize the value in novelties to adopt them. As in the previous phase, the implementation can also generate feedback for the previous phases, which can lead to improvements and new forms of solutions (i.e., an incremental innovation process of the solution).

\subsection{Techniques for Idea Generation}

The idea generation is a process that companies typically use to generate innovative ideas for new products or generate solutions to difficult problems. This process is characterised by the exchange of ideas between a group of people, where the best idea will be selected, an implementation plan is created, and finally, its implementation is performed (Forbes, 2015). In this sense, there are many

Jonas Queiroz, Paulo Leitão, Joseane Pontes, André Chaves, Javier Parra-Domínguez and María E. Perez-Pons A Quality Innovation Strategy for an Inter-regional Digital Innovation Hub
ADCAIJ: Advances in Distributed Computing and Artificial Intelligence Journal Regular Issue, Vol. 9 N. 4 (2020), 31-45 eISSN: 2255-2863 - https://adcaij.usal.es Ediciones Universidad de Salamanca - CC BY-NC-ND 
methodologies and techniques for generating ideas, and one of the most widely used methodology for structuring new ideas is the Design Thinking (Cankurtaran and Beverland, 2020).

According to (Cankurtaran and Beverland, 2020), Design Thinking is a systemic and anthropocentric oriented methodology aimed at generating innovation, first used in 1969 by Herbert Simon and later formalized by Simon Brown in 2008. Its essence is to obtain innovation focusing on the client's needs rather than the problem and may vary in the number of steps to consolidate the approach. In general, it comprises five stages: Create empathy to understand the client, Define, Idealise, Prototype, and Test.

Specifically, in the idea generation sessions during the Design Thinking process, specific techniques are applied to foster the creative process of creating innovative ideas, namely:

a) Brainwriting: in this technique, each participant anonymously, writes their ideas on cards. These will be shared between the participants, and every participant can add new points to the original idea or argue critically (Amabile and Pratt, 2016).

b) Mindmapping: it is a graphical technique that allows to imagine links between various pieces of information or ideas. To do this, the various ideas that emerge are written and then linked through lines, creating a web of relationships between the ideas (Baregheh et al., 2009).

c) Brainstorming: is an idea generation technique commonly used to pool resources for new ideas, and is widely used in group situations and on a trial suspension basis (Crossan and Apaydin, 2010). Usually, it starts by exposing a problem to get ideas for its resolution. Most brainstorming sessions make use of post-its that allow participants to have more visibility on ideas and speed up the process, making it more appealing (Edison et al., 2013).

d) Reverse Brainstorming: Unlike the previous one, it is a technique that asks participants to think of various ways to cause a problem. In the end, there will be a list of how to create problems, and the next step will be to think of ways to solve them (Amabile and Pratt, 2016).

\subsection{Process for Measuring the Quality of Innovation}

Measuring and monitoring the quality of innovation during the innovation process is essential to ensure the success of innovation and identify what can be improved/adapted in the innovation process. Innovation can be measured through the collection of quantitative and qualitative data generated during the innovation process. The Oslo Manual (OECD/Eurostat, 2018) presents a guideline with recommendations to measure some aspects of the innovation process. Examples of quantitative indicators include the total investment in innovation, the market share, the revenues obtained from selling the innovation (product or service), the labour use (human resources), the material consumption, the energy consumption, the time needed to reach a marketable solution, and the payback period. On the other hand, qualitative data include: benefits of innovation, sources of information and ideas for innovation, and diffusion or scope of innovation. According to (OECD, 2010) there are five key actions for a measurement agenda for innovation:

i. Improve the quality of measurement of wider innovations and their relationship with macroeconomic performance.

ii. Invest in a comprehensive and high quality data architecture to measure the impacts of innovation.

iii. Recognise the role of innovation in the public sector and promote its measurement.

Jonas Queiroz, Paulo Leitão, Joseane Pontes, André Chaves, Javier Parra-Domínguez and María E. Perez-Pons A Quality Innovation Strategy for an Inter-regional Digital Innovation Hub
ADCAIJ: Advances in Distributed Computing and Artificial Intelligence Journal Regular Issue, Vol. 9 N. 4 (2020), 31-45 eISSN: 2255-2863 - https://adcaij.usal.es Ediciones Universidad de Salamanca - CC BY-NC-ND 
iv. Promote the design of new statistical methods and interdisciplinary approaches to data collection.

v. Promote the measurement of innovation for social objectives and the social impacts of innovation.

Concerning the metrics for innovation, the Portuguese National Innovation Agency (Agencia Nacional de Inovação, 2020) proposes 44 indicators to measure the innovation of projects from the following areas: Human Resources, Excellence and Attractiveness of the R\&D System, Financing R\&D and Innovation, Intellectual Property, Innovative Companies, Economic Impacts, Balance of Payments Technology (BPT) and Information Society. This proposal aims to develop actions aimed at supporting technological and business innovation in Portugal, contributing to the consolidation of the National Innovation System (NIS) and strengthening the competitiveness of the national economy in global markets.

In addition, according to (Kristiansen and Ritala, 2018) there are some common metrics used for innovation projects: Net Present Value, Return on Investment, Percentage of profits from products less than one year old, Total patents filed/pending/expected, Time-to-market and Project Success or Failure. But these authors propose new specific indicators for projects concerning radical innovation, which are focused on market orientation, learning, and future opportunities, as well as resource dedication. Examples of indicators pointed out in this study are Potential of Market, Existing links to markets, Finding new market needs, Deliverance of real benefits to the customer, Learning per dollar spent, Potential for growth in existing business segments Termination report quality, Ability to use and grow core competencies, Active projects supported; Intangible resources, and Tangible resources and External resources.

In this sense, the importance of measuring the quality of innovation is perceived, either through common indicators present in the literature or through the proposition of indicators, according to the strategy or type of innovation proposed for a project, product, or service. Only by measuring innovation using indicators will be possible to build up the history of the innovation and then monitor its quality.

\section{A Strategy for Managing the Quality of Innovation in the Inter- regional DIH}

An innovation management strategy aims to create the circumstances and the necessary apparatus to foster innovation, also offering the appropriate tools to make the most of the opportunities for improvement. Innovation, in turn, is derived from the needs that arise in the process of society's evolution, and is essential to increase the probability of success, competitiveness, prosperity and even the survival of many organizations.

The inter-regional DIH to be created will comprise the ICT research centers and DIHs from the DISRUPTIVE consortium. Based on their individual strategies, the pillars of a methodology for managing the quality of innovation within the inter-regional DIH are the following:

i. Definition of an Innovation Strategy;

ii. Definition and implementation of an Innovation Management Process;

iii. Monitoring and evaluation of the quality of innovation.

Jonas Queiroz, Paulo Leitão, Joseane Pontes, André Chaves, Javier Parra-Domínguez and María E. Perez-Pons A Quality Innovation Strategy for an Inter-regional Digital Innovation Hub
ADCAIJ: Advances in Distributed Computing and Artificial Intelligence Journal Regular Issue, Vol. 9 N. 4 (2020), 31-45 eISSN: 2255-2863 - https://adcaij.usal.es Ediciones Universidad de Salamanca - CC BY-NC-ND 
In the definition of them, an important aspect that should be considered is the mechanisms to enable and take advantage of the cooperation among the associated research centers or DIHs. For instance, the innovation strategy can consider the use of open innovation approaches, while the innovation management process should consider knowledge sharing and technology transfer.

Besides these pillars, the methodology also considers two main actors: the Innovation Manager and the Project Leader, who play important roles to assure the success and quality of an innovation project.

Figure 4 provides an overview of the proposed methodology, where the inter-regional DIH is formed by the cooperation between several research centers and DIHs that work together to promote the digital transformation in the regional companies (Rissola and Sörvik, 2018). Additionally, the innovation strategy of each member of the inter-regional DIH should consider the cooperation aspects.

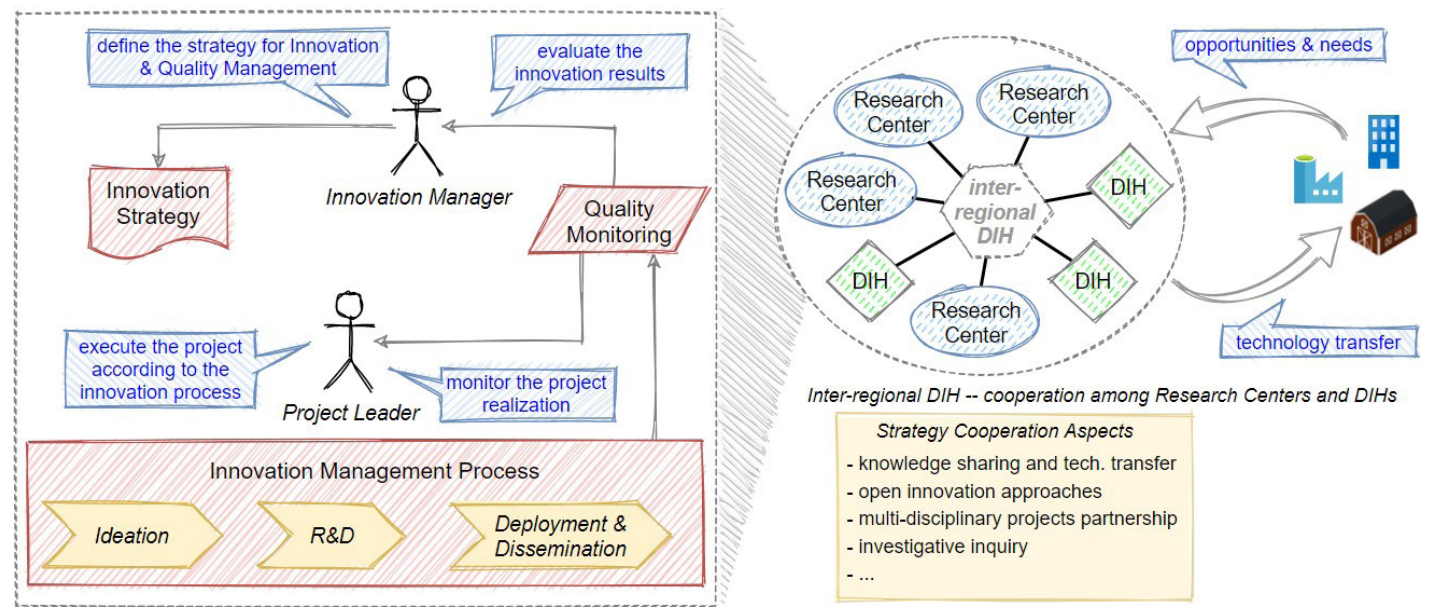

Figure 4: Methodology for quality management of innovation in the inter-regional DIH.

\subsection{Definition of an Innovation Strategy}

The challenge today is to create organized and systematic processes in organizations to ensure that they continuously produce innovative and successful results for their customers and that they lead to the creation of a culture of innovation. The generation, selection, and implementation of ideas is the backbone of this process, accompanied by other components of equal importance.

The first is the definition of a future state of innovation that supports the organization's growth ambitions, understanding leadership aspects, reasons for seeking innovation, and also the scope and type of organizational changes needed. Another aspect is related to design this innovation system for when a capacity is created, be something that lasts and supports the organization's growth ambitions. And finally, it is to create and execute a phased plan, first assuming the critical barriers and then planning the implementation of this innovation system. Also, one should not overlook a fundamental element in innovation, which is the search for opportunities, offering solutions to the unsatisfied needs of end-users, and, above all, those that end users are not able to express themselves.

It is worth clarifying that innovation is not R\&D. The process of R\&D (Research - applied, and Development - experimental) can result in products that do not reach the market or in processes that are

Jonas Queiroz, Paulo Leitão, Joseane Pontes, André Chaves, Javier Parra-Domínguez and María E. Perez-Pons A Quality Innovation Strategy for an Inter-regional Digital Innovation Hub
ADCAIJ: Advances in Distributed Computing and Artificial Intelligence Journal Regular Issue, Vol. 9 N. 4 (2020), 31-45 eISSN: 2255-2863 - https://adcaij.usal.es Ediciones Universidad de Salamanca - CC BY-NC-ND 
not appreciated by the market. If this is the case, there is no innovation. This illustrates the importance of the adoption of quality management strategies along all the innovation process, not only to mitigate issues that can lead to outcomes that are not appreciated and effectively adopted but also to assure the wide adoption and value generated.

Considering that both, DIHs and research centers, focus on the development and application of disruptive and advanced ICT to support and promote the digital transformation in industries, it is expected that innovation will focus on an incremental and disruptive model at the product and/or process level (according to the definitions in (OECD/Eurostat, 2018)). Therefore, the innovation strategy of each member of the inter-regional DIH, besides cover their internal goals, should also consider the cooperation aspects expected in the inter-regional DIH. For instance, it should be aligned with knowledge sharing and technology transfer models, open innovation approaches, and multi-disciplinary innovation projects partnership (see Figure 4).

The promotion of a culture of innovation is important for the growth and survival of any company, given that without innovation they can fail to evolve and follow the market trends, becoming less competitive and consequently being overtaken by the competition. In the case of research centers and DIHs, the innovation culture should have even more attention given that these kinds of organizations represent state-of-the-art technology advancements. In this case, the innovation culture must be allied to the innovation strategy, where the Innovation Manager together with the Project Leaders play an important role to assure its effectiveness, i.e., that it continues to promote the seek and development of innovative ideas by the organization employees.

The promotion of a culture of innovation can be achieved through various techniques that mainly consider organizational and social aspects, regarding special activities and events that stimulate the communication and interaction between multidisciplinary people in order to generate new ideas and projects. Additionally, it is combined with the promotion of incentives and rewards on the realization of successful innovative ideas and projects, that should be carefully managed in order to prevent competitiveness from interfering with cooperation. Regarding the cooperation between multiple organizations, as in the inter-regional DIH, the culture of innovation should include techniques, for instance, to encourage open innovation when internal capabilities are exceeded, the sharing of knowledge and skills or use investigative inquiry techniques.

And finally, the monitoring of the quality of innovation should also be considered in the definition of the innovation strategy. It plays an important role, not only to assure the successful development and deployment of innovation projects, but also that the innovation strategy is effective. In this sense, the results of the process of innovation quality evaluation should be used to continuously improve and adapt the aspects of the innovation strategy that shown to be not effective, thus also supporting the market dynamics that are constantly evolving and requiring new approaches and technologies. In this context, the monitoring of the quality of innovation should be carried out by means of indicators that reflect:

- The lessons learned in the process of innovation (both successes and failures).

- The knowledge management for the dissemination of the results of the innovation process.

- The encouragement of the coexistence of structures oriented to flexibility and creativity simultaneously to the existing (traditional) management structure, based on hierarchy, specialization, compliance with established standards or focused on control and efficiency, etc..

- The product or process improvement (either incremental or disruptive).

Jonas Queiroz, Paulo Leitão, Joseane Pontes, André Chaves, Javier Parra-Domínguez and María E. Perez-Pons A Quality Innovation Strategy for an Inter-regional Digital Innovation Hub
ADCAIJ: Advances in Distributed Computing and Artificial Intelligence Journal Regular Issue, Vol. 9 N. 4 (2020), 31-45 eISSN: 2255-2863 - https://adcaij.usal.es Ediciones Universidad de Salamanca - CC BY-NC-ND 


\subsection{Definition and Implementation of the Innovation Management Process}

The innovation management process is a cyclical and continuous process that starts from the identification of opportunities, where a well-constructed strategic plan that can be supported by different frameworks and tools, guides the work to the areas of interest, according to the defined strategy.

A careful observation of the environment makes possible the identification of dogmas and beliefs (orthodoxies) in the organization that can be identified - following the steps indicated in (Skarzynski and Gibson, 2008) - and confronted, as well as, discontinuities and trends that offer new opportunities and the unmet needs of end users and, above all, those where end users are not able to express themselves.

The innovation management process includes 3 main stages (Ideation, R\&D, Deployment \& Diffusion), as illustrated in Figure 4 (left) and previously discussed in Section 2.2.

The Ideation stage encompasses the idea generation and validation process. In this stage the use of frameworks and tools are essential to assure the quality of the ideas produced, and consequently the rate of success of the innovation to be produced. Additionally, the participation of multiple partners with different skills from the inter-regional DIH in the related activities can further support and validate the outputs of this process. In this context, this stage covers the following aspects:

- Use of methodologies to generate ideas, for example, Brainstorming (simpler) or Design Thinking (more advanced), and use of co-creation with multidisciplinary teams (e.g., researchers, students, entrepreneurs and business associations).

- Promotion of out-of-the-box thinking and adoption of knowledge cross-fertilization techniques (i.e. the application of established technologies/techniques in a different field of application).

- Performing SWOT analyses (Strengths, Weaknesses, Opportunities, and Threats), both for the problem and for the solution.

- Use the SMART (Specific, Measurable, Achievable, Relevant, and Time-Bound) criteria to refine and evaluate the ideas and project goals.

- Carrying out a technical feasibility analysis of the ideas, by a board of experts.

- Realization of market feasibility analysis and evaluation of the acceptance of ideas, by a mixed board (composed by entrepreneurs, clients, commercial/industrial associations and consultants of the geographic region covered by DIH).

- Prior assessment of technological maturity (e.g., through the Technology Readiness Level) prior to employment in the organization.

The $R \& D$ stage encompasses the implementation of the ideas towards the development of the prototypes and the whole innovation solution. In this stage, it is important to continuously monitor the development of the activities in order to assure the quality and success of the solution. A special attention should be taken when the project involves the collaboration of multiple partners, as in the case of the inter-regional DIH. In this context, this stage covers the following aspects:

- Definition of an activity plan, containing the delineation of tasks, their starting and ending dates, the scheduling of periodic follow-up meetings and the definition of milestones (for example, using a Gantt diagram).

- Using project management techniques, e.g., the critical path methodology, the cause and effect diagram, the project model canvas and the agile project management framework Scrum.

Jonas Queiroz, Paulo Leitão, Joseane Pontes, André Chaves, Javier Parra-Domínguez and María E. Perez-Pons A Quality Innovation Strategy for an Inter-regional Digital Innovation Hub
ADCAIJ: Advances in Distributed Computing and Artificial Intelligence Journal Regular Issue, Vol. 9 N. 4 (2020), 31-45 eISSN: 2255-2863 - https://adcaij.usal.es Ediciones Universidad de Salamanca - CC BY-NC-ND 
- Rapid prototyping and constant iteration with the user of the product or technology under development.

- Integration between DIH and research centers, fostering R\&D activities and the transfer of knowledge, technology and innovation. This can be achieved by the realization of periodic project meetings to monitor the progress of the project, regarding the tasks of each partner and the organization of periodic solution integration meetings to integrate and test the components developed by different parts, to mitigate compatibility and interoperability problems in the final solution.

The last stage of the Innovation Management Process, comprises the solution Deployment and the Dissemination of its results. The first, besides to set the solution to work in a production environment, also includes monitoring and post deployment tasks that are essential to assure the success of the solution, regarding its acceptance. The output of this process can provide valuable quality measurements that can be used to improve or redefine the innovation strategy. In this context, it includes the following specific aspects:

- The correction of unseen problems and implementation of new features, as well as the customization of the solution according to the needs of the final customer.

- Monitoring and evaluation of the customer journey from the solution awareness to the usage experience and satisfaction, e.g., to learn the user preferences to develop improvements, and also for the generation of ideas for new innovative products.

In this stage, the Dissemination of the solution results is also important to promote its adoption and obtain the expected value for the organization. However, one of its main goals is to attract new opportunities and the attention of investors and other stakeholders that can provide funds to further develop the ideas, as well as new innovation projects. Additionally, it can also support the creation of new partnerships with other entities that can foster the development of new knowledge and the sharing of skills. In this context, it includes the following specific aspects:

- Participation in technology, innovation and business fairs.

- Promoting mentoring activities.

- Participation in innovation project calls.

- Participation in workshops, scientific events, training courses and hackathons.

\subsection{Monitoring and Evaluation of the Quality of Innovation}

A key actor in the definition and implementation of the innovation strategy is the Innovation Manager, who has, among others, important responsibilities, some of which are shown in Figure 5. It is important to emphasize his critical functions regarding the implementation and management of the organization's innovation strategy. In this sense, the Innovation Manager should have multidisciplinary skills and technology related knowledge.

One of his responsibilities is the management of the innovation culture inside the organization that requires the continuous monitoring and managing of the innovation activities and personnel to ensure the constant flow of ideas and realization of projects. He is also responsible to obtain financing support for the projects, not only in the private sector, e.g., by finding and contacting companies but also through public funding programs, e.g., related to national and international research project

Jonas Queiroz, Paulo Leitão, Joseane Pontes, André Chaves, Javier Parra-Domínguez and María E. Perez-Pons A Quality Innovation Strategy for an Inter-regional Digital Innovation Hub
ADCAIJ: Advances in Distributed Computing and Artificial Intelligence Journal Regular Issue, Vol. 9 N. 4 (2020), 31-45 eISSN: 2255-2863 - https://adcaij.usal.es Ediciones Universidad de Salamanca - CC BY-NC-ND 


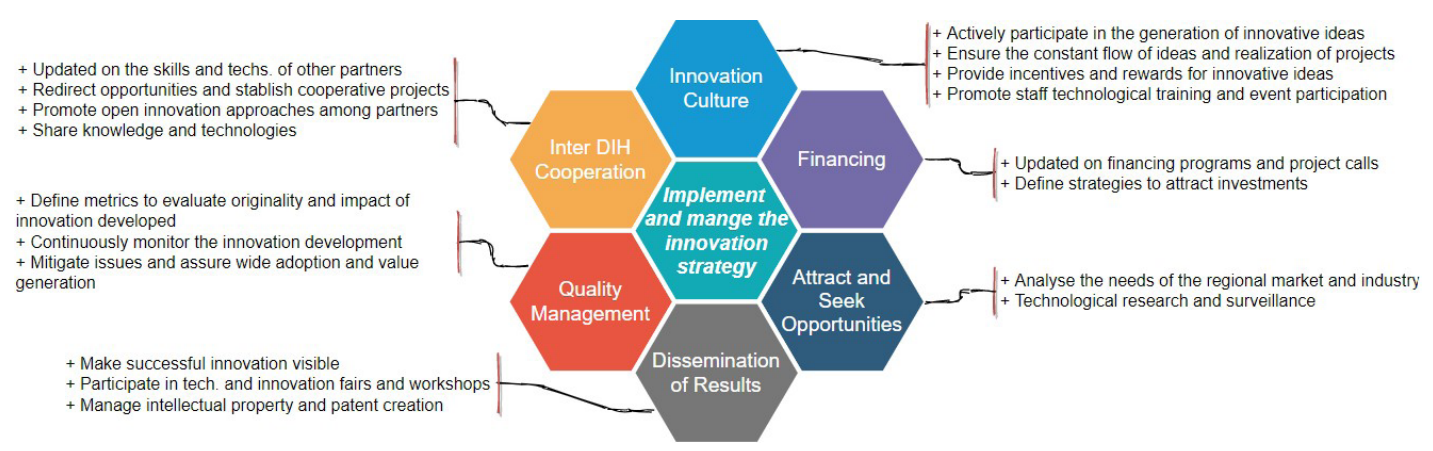

Figure 5: Innovation Manager responsibilities in the realization of the innovation strategy.

calls. In the same sense, he should adopt strategies to continuously attract and seek opportunities to develop innovative solutions. This means he should be updated on the state-of-the-art technological advancements and market trends. Both investments and new opportunities can be obtained by the proper dissemination of the results of successful projects. In this sense, make the innovation visible is very important and can be achieved, e.g., by participation in technological and scientific events.

As part of the inter-regional $D I H$, the innovation manager has special responsibilities, being able to manage the internal strategies and interests to promote and harmonize the cooperation with the other partners. This requires an updated knowledge about the skills of the inter-regional DIH members, in order to establish cooperative projects and strategies to share knowledge and technologies.

An important aspect of an innovative solution is its quality that can be measured by its acceptability and value generated. In this context, the quality management of the innovative solutions is also a responsibility of the Innovation Manager that should not only define the quality metrics but also actively participate in all the stages of the innovation development, continuously monitoring and evaluating the quality of the innovation. To support these tasks, the innovation manager can use different monitoring techniques and frameworks, selecting the proper metrics according to the type of innovation being developed.

However, the execution of these tasks can be supported by some innovation facilitators, who are employees, coordinated by him, from different departments responsible for promoting innovation in the different units of the organization. And, as support, there may be committees and innovation teams, which are the essential linking element to achieve the participation of all levels of the organization in the innovation process. The essence of its composition is the diversity of its members, in terms of their characteristics and background, their training, the hierarchy they occupy in the company, their social status, among others.

The innovation facilitators actively participate in the development of the activities contemplated in the innovation management process, especially in the ideation and implementation stages. The responsible in charge of this process is the Project Leader, as illustrated in the Figure 4. With a management position, he has an important role to ensure the successful development of the project, and mainly that the final solution will achieve the desired quality levels. In this context, the Project Leader should support the Innovation Manager in the monitoring and measurement of the quality attributes.

Jonas Queiroz, Paulo Leitão, Joseane Pontes, André Chaves, Javier Parra-Domínguez and María E. Perez-Pons A Quality Innovation Strategy for an Inter-regional Digital Innovation Hub
ADCAIJ: Advances in Distributed Computing and Artificial Intelligence Journal Regular Issue, Vol. 9 N. 4 (2020), 31-45 eISSN: 2255-2863 - https://adcaij.usal.es Ediciones Universidad de Salamanca - CC BY-NC-ND 

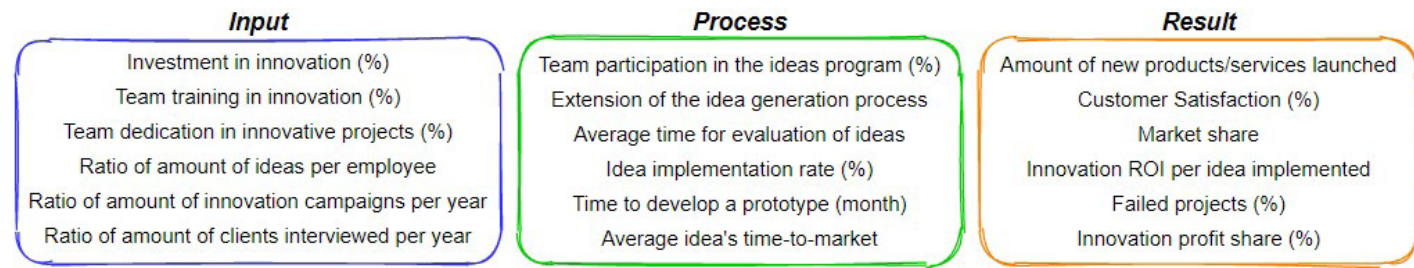

Figure 6: Examples of indicators per type of metric.

The set of quality metrics should be chosen carefully and according to the guidelines established in the formulation of the innovation strategy, being fundamental to evaluate the progress of the innovation process and its results. According to (Guzmán et al., 2017), metrics are usually defined in association with the different phases of an innovation macro-process and can be divided into input metrics, process metrics, result metrics.

Figure 6 presents some examples of indicators according to the type of metric. The input metrics can be directly mapped into the general tasks regarding the promotion of the innovation culture together with the first stage of the innovation management process, i.e. the ideation. While the process and result metrics can be associated to the R\&D and Deployment \& Dissemination stages, respectively. Alongside the metrics, it is important to define as indicators the objectives to be achieved, e.g., setting medium-term objectives as $X$ new ideas, and $Y$ innovative projects.

\section{Conclusions}

Along with the various industrial revolutions, the need for improvements in new products, processes, and services led to incremental and radical innovations aiming to maintain the companies' competitiveness. With the 4th industrial revolution, the need for improvements in the various economic sectors still requires constant innovation, supported by the principles and technologies associated with Industry 4.0. In this way, the technological and digital trends affect the profile and needs of consumers to face the Digital Era and, therefore, of organizations that need to seek ways to create and innovate their products, processes, and services based on these new needs or even transcend the expectations of consumers. In this emerging context, DIHs are an instrument that can assist companies, small or large, high-tech or not, to take advantage of digital opportunities to evolve, innovate, and increase their competitiveness.

Having this in mind, this paper describes a strategy for managing the quality of innovation in an inter-regional DIH that has been created as part of the DISRUPTIVE project and integrates several research centers and DIHs located in the northern region of Portugal and Castilla y León (CyL-PN). This strategy raises and discusses several aspects that concern the cooperation of the associated partners to promote innovation, knowledge creation, and technology transfer to improve and support the digitization of local companies.

The strategy has been implemented along the last year of the DISRUPTIVE project through the realization of some activities, including the identification of the needs of the region and the skills of the research centers and DIHs regarding the disruptive ICT technologies. Additionally, some networking events and workshops were organized to promote cooperation and knowledge sharing among the members, as well as to show the new technologies being developed to the local companies. Also in

Jonas Queiroz, Paulo Leitão, Joseane Pontes, André Chaves, Javier Parra-Domínguez and María E. Perez-Pons A Quality Innovation Strategy for an Inter-regional Digital Innovation Hub
ADCAIJ: Advances in Distributed Computing and Artificial Intelligence Journal Regular Issue, Vol. 9 N. 4 (2020), 31-45 eISSN: 2255-2863 - https://adcaij.usal.es Ediciones Universidad de Salamanca - CC BY-NC-ND 
this context, some ongoing activities include the realization of several training and mobility programs for researchers, aiming the generation of specialized knowledge to support the technology needs of the region.

The next steps include the organization of more activities of this kind, also including mentoring activities given by ICT experts, to identify and attract companies interested in developing joint projects.

\section{Acknowledgments}

This work has been partially supported by the European Regional Development Fund (ERDF) through the Interreg Spain-Portugal V-A Program (POCTEP) under grant 0677_DISRUPTIVE_2_E (Intensifying the activity of Digital Innovation Hubs within the PocTep region to boost the development of disruptive and last generation ICTs through cross-border cooperation). The authors would like to thank the DISRUPTIVE partners that supported the conception and consolidation of the innovation methodology, namely USal (Universidad de Salamanca), UVa (Universidad de Valladolid), ISEP (Instituto Superior de Engenharia do Porto), IPB (Instituto Politécnico de Bragança), Fundación CARTIF, PRODUTECH, and ICE (Instituto para la Competitividad empresarial de Castilla y León).

\section{References}

Agencia Nacional de Inovação, 2020. Ranking e Indicadores de Inovação. URL: https://www.ani.pt/pt/ avaliaçao-e-monitorizacao/monitorizaç ao/rankings-e-indicadores. (accessed:29.11.2020).

Amabile, T. M. and Pratt, M. G., 2016. The dynamic componential model of creativity and innovation in organizations: Making progress, making meaning. Research in Organizational Behavior, 36:157183.

Baregheh, A., Rowley, J., and Sambrook, S., 2009. Towards a multidisciplinary definition of innovation. Management Decision. Research in Organizational Behavior, 47:1323-1339.

Blanchet, M. and Rinn, T., 2016. The Industrie 4.0 transition quantified. Technical report, Roland Berger $\mathrm{GmbH}$.

Cankurtaran, P. and Beverland, M., 2020. Using design thinking to respond to crisis: B2B lessons from the 2020 COVID-19 pandemic. Industrial Marketing Management, 88:255-260.

Carpinetti, L., 2016. Gestão da Qualidade: Conceitos e Técnicas.

Crossan, M. and Apaydin, M., 2010. A multi dimensional framework of organizational innovation: A systematic review of the literature. Journal of Management Studies, 47(6):1154-1191.

Edison, H., Bin Ali, N., and Torkar, R., 2013. Towards innovation measurement in the software industry. Journal of Systems and Software, 86:11390-1407.

European Commision, 2020. Shaping Europe's digital future - Digital Innovation Hubs (DIHs) in Europe. URL: https://ec.europa.eu/digital-single-market/en/digital-innovation-hubs. (accessed:29.11.2020).

Forbes, 2015. What's the Difference Between Invention and Innovation? URL: https://www.forbes. com/sites/jacobmorgan/2015/09/10/whats-the-difference-between-invention-and-innovation. (accessed:29.11.2020).

Garvin, D. A., 1992. Gerenciando a Qualidade: a visão estratégica e competitiva.

Jonas Queiroz, Paulo Leitão, Joseane Pontes, André Chaves, Javier Parra-Domínguez and María E. Perez-Pons A Quality Innovation Strategy for an Inter-regional Digital Innovation Hub
ADCAIJ: Advances in Distributed Computing and Artificial Intelligence Journal Regular Issue, Vol. 9 N. 4 (2020), 31-45 elSSN: 2255-2863 - https://adcaij.usal.es Ediciones Universidad de Salamanca - CC BY-NC-ND 
Geissbauer, R., Vedso, J., and Schrauf, S., 2016. Industry 4.0: Building the digital enterprise. Technical report, PWC.

Guzmán, A., Yoguel, G., and Llamas, I., 2017. Innovación en América Latina. Harvard Business Press.

Kristiansen, J. N. and Ritala, P., 2018. Measuring radical innovation project success: typical metrics don't work? Journal of Business Strategy, 39:34-41. ISSN 0275-6668.

OECD, 2010. Promote the measurement of innovation for social goals and of social impacts of innovation. URL: https://www.oecd.org/site/innovationstrategy/45392693.pdf. (accessed:29.11.2020).

OECD/Eurostat, 2018. Oslo Manual 2018: Guidelines for Collecting, Reporting and Using Data on Innovation, 4th Edition, The Measurement of Scientific, Technological and Innovation Activities.

Paladini, E. P., 2012. Gestão da Qualidade: Teoria e Prática.

Rissola, G. and Sörvik, J., 2018. Digital Innovation Hubs in Smart Specialisation Strategies. Publications Office of the European Union, Luxembourg.

Skarzynski, P. and Gibson, R., 2008. Innovation to the Core: A Blueprint for Transformating the Way Your Company Innovates. Editorial Biblioteca Nueva. 